ALPHA N 26 / Julio 2008 (89-99)

ISSN 0716-4254

http://alpha.ulagos.cl

\title{
PERIODISMO, FICCIÓN Y REALIDAD: A PROPÓSITO DE TODO SON PREGUNTAS, EL OJO DE LA CERRADURA Y SOMBRAS SOBRE SOMBRAS DE JUAN JOSÉ MILLÁS
}

Journalism, Fiction and Reality in Juan José Millás' Todo son preguntas, El ojo de la cerradura, and Sombras sobre sombras

Teresa González Arce*

\section{Resumen}

Durante los veranos de 2004, 2005 y 2006, el escritor español Juan José Millás publicó una serie de artículos que más tarde dieron lugar a tres recopilaciones tituladas Todo son preguntas, El ojo de la cerradura y Sombras sobre sombras. Entendidos, a la vez, como preguntas y respuestas suscitadas por fotografías aparecidas en la prensa, los tres volúmenes dan cuenta de una poética sostenida por una concepción espacial del mundo que, de manera explícita, remite a la imagen platónica de la caverna. El escritor utiliza la ficción literaria como una herramienta de interpretación de la realidad - representada aquí por la serie de fotografías- $y$, al hacer esto, pone en entredicho los límites entre la verdad y las apariencias. Agregar sombras a un mundo poblado por simulacros, parece decir Millás, es la única forma de entender algo en este galimatías en el que vivimos.

Palabras claves: Juan José Millás, periodismo y literatura, literatura española.

\begin{abstract}
In the summers of 2004, 2005 and 2006 the Spanish writer Juan José Millás published a series of articles that later appeared in three volumes titled Todo son preguntas, El ojo de la cerradura and Sombras sobre sombras. His essays are best understood as a meditation about press photos that inspire both questions and answers, expressing a poetics grounded in a spatial conception of the world that explicitly invokes the platonic image of the cave. The writer utilizes literary fiction as a tool to interpret reality - represented here in the series of photos - and, in so doing, problematizes the limits between truth and appearance. It is only by adding shadows to a world replete with simulacra, Millás seems to say, that we can make any sense of the world at all.
\end{abstract}

Key words: Juan José Millás, journalism and literature, Spanish literature. 


\section{Teresa González}

Publicados originalmente en la Revista de Agosto del diario El País durante los veranos de 2004, 2005 y 2006, los artículos de Juan José Millás - recogidos por la editorial Península bajo los títulos de Todo son preguntas (2005), El ojo de la cerradura (2006) y Sombras sobre sombras (2007)_ ponen de manifiesto que la vocación de construir espacios es, en más de un sentido, el sustrato de la poética de Millás. Por una parte, el hecho mismo de recopilar textos aparecidos en la prensa cotidiana confirma el carácter sensible de una escritura que, literalmente, ocupa espacio, ya que se trata de ediciones en pasta dura que resaltan la materialidad de la escritura de Millás. Por la otra, los artículos dan cuenta de una concepción eminentemente espacial del mundo: de un mundo que se entiende como espacio y al que se interroga desde una subjetividad que es, también, entendida en su dimensión espacial. En el caso de Millás, forma y fondo se complementan en la medida en que lo escrito - el diálogo con un mundo concebido como espacio- se ve confirmado en los contornos que la palabra va dibujando en el momento de su enunciación.

Según los prólogos a Todo son preguntas y a El ojo de la cerradura, estos libros fueron concebidos como álbumes, es decir, como composiciones hechas con materiales de distinta naturaleza - fotografías y textosencuadernados según un orden subjetivo establecido por Millás. En cada uno de ellos hay una serie de 31 fotografías (una por cada día del mes de agosto) procedentes de la prensa española que, de una u otra manera, consiguieron interpelar al autor por tratarse de imágenes que, "sin dejar de ser profesionales y de referirse a asuntos públicos, irradian un halo de fotografía familiar, de representación íntima" (2006:11). Conviene mencionar que ese "halo de fotografía familiar" está estrechamente relacionado con lo que el autor considera la capacidad de las imágenes para convertirse en "iconos de una época" (2005:11).

Si el álbum funge como modelo ético y estético de las compilaciones es, sobre todo, debido a la voluntad ordenadora de quien selecciona y organiza las imágenes. Al comparar su tarea con la de un coleccionista de sellos para quien importa menos alcanzar la posteridad que "el placer inmediato de ordenar la vida, la realidad, el árbol genealógico" (2006:10), Millás enfatiza el poder que la mirada del escritor tiene sobre la realidad que lo rodea y, en particular, sobre la avalancha de imágenes publicadas por la prensa. Entre todas las fotografías, el escritor seleccionó sólo aquéllas que, al interrogarlo, lo llevaron a formularse esas preguntas que dan título a la segunda compilación. "Todo son preguntas", anota el autor al final de algunos de sus artículos. Y es que, efectivamente, todo en los tres libros son preguntas, incluyendo los textos que acompañan a las fotografías. 


\section{Periodismo, ficción y realidad}

Tanto la selección de imágenes como la escritura de los textos que las acompañan son parte de ese trabajo interpretativo que toma forma gracias a la metáfora del álbum. "Las fotografías de la prensa diaria", dice Millás, "forman parte del álbum de familia de una sociedad. Al repasarlas, nos reconocemos en ellas y hacemos comentarios semejantes a los que se efectúan frente a las páginas del álbum familiar" (2005:12). Reconocerse en las fotografías y dejarse interrogar por ellas es, así, una manera de intervenir en la realidad fragmentada que presentan las imágenes fotográficas.

En este sentido, es interesante recordar que, para Susan Sontag, la fotografía "atomiza" la realidad — esa realidad que, paradójicamente, parece más "disponible" al ser presentada en fotografías - y vuelve necesaria la intervención de un intérprete. Al negar la interrelación entre los sucesos ocurridos en el mundo, al fragmentar la realidad, la fotografía confiere a las cosas el carácter de un misterio e invita al espectador a interrogarse sobre sus múltiples significados. "Las fotografías, que en sí mismas no explican nada", observa Sontag en un ensayo titulado "En la caverna de Platón", "son inagotables invitaciones a la deducción, la especulación y la fantasía" (41-42).

Sacadas de su contexto, las fotos incluidas en las tres compilaciones necesitan la palabra de ese "coleccionista de sellos" o formador de álbumes que es Millás, ya no para recuperar su significado original sino para expresar una verdad que desmienta las apariencias. Ciertamente, los artículos que acompañan las fotografías sitúan a éstas en la circunstancia específica en la que se inscribían originalmente, de modo que cualquier lector $-\mathrm{y}$ no sólo aquéllos que siguieron la prensa española de 2004 a 2007- pueda comprender los textos. Sin embargo, no es este tipo de información lo que constituye el punto central de la prosa de Millás pues, si bien es cierto que con el paso del tiempo algunas imágenes se han vuelto crípticas y necesitan de un texto explicativo, los artículos de Millás trascienden la mera recuperación del sentido original de las fotografías.

Sombras sobre sombras es un título elocuente sobre la concepción del mundo que subyace en los artículos de Millás. Lo es también, en este mismo sentido, la referencia a la parábola platónica de la caverna que hace el autor en el prólogo. El funcionamiento de la cámara fotográfica o, mejor aún, de su antecedente - la cámara oscura - no es sino la puesta en abismo de un fenómeno que se repite a otras escalas. Platón decía, como sabemos, que el mundo era una gran caverna en la cual se proyectaban las sombras de las formas sensibles que existían en el exterior. Para Millás, no sólo el universo funciona así, sino también todos y cada uno de sus habitantes: "Comprendí", leemos en el prólogo a Sombras sobre sombras, "que no otra cosa somos cada uno de nosotros: cámaras oscuras en las que penetran las imágenes del 


\section{Teresa González}

mundo, del mundo, atrapado a su vez en una cámara oscura mayor" (2007:11).

La naturaleza de la imagen fotográfica aparece así en su calidad de simulacro de una realidad que es, ya en sí misma, un simulacro. Y, puesto que la mirada, como la obertura practicada en la cámara oscura, nos confronta a otra simulación, el afán por acceder a la verdad se revela como una tarea casi imposible. Aún así, Millás entiende la escritura de estos artículos como una búsqueda y como un intento de comprensión de la realidad. "El texto que acompaña a cada una de las fotos que se exponen a continuación", escribe Millás en el prólogo a Sombras sobre sombras, "no es más que un modo de tantear entre las sombras el sentido de los bultos de los que estamos rodeados" (2007:11).

El verbo "tantear", utilizado aquí en el sentido de averiguar o de conocer "a tientas", resulta significativo al relacionarlo con su famoso prólogo a la Trilogía de la soledad (1996), titulado "El síndrome de Antón”. En él, Millás afirma que el escritor padece algo similar a ese extraño síndrome que consiste en creer que se ve o, mejor aún, en ver, cuando en términos clínicos se es completamente ciego. Según Millás el escritor, como el enfermo, es un ciego que no sabe que no ve. Para Millás, escribir consiste en conseguir que la "realidad exterior" encuentre una especie de continuidad con el mundo que se proyecta - de nuevo Platón — dentro de la "bóveda craneal", de modo que

Escribir es una práctica de ciegos, una técnica cuyo fin último consistiría en que la calle de fuera se convirtiera en una prolongación de la de dentro, o al revés, de manera que no chocaras con los muros de un sitio ni del otro aunque mantuvieras los ojos abiertos. O cerrados" (1996:9$10)$.

A diferencia de Platón, para quien la ceguera de los prisioneros de la caverna es una deficiencia que el recuerdo y el conocimiento $-\mathrm{O}$ el conocimiento basado en la memoria - deberían ayudar a combatir, para Millás no ver - esto es, el no ver sólo la realidad exterior- es una cualidad e, incluso, una condición indispensable para aventurarse en el desciframiento de las apariencias. No es que la mirada carezca de importancia, ni que todas las formas de mirar sean iguales. "Todo el mundo tiene una cámara de fotos, pero no todo el mundo tiene mirada", dice Millás para dejar en claro que hay imágenes, como las que él escogió para escribir sus artículos, con las cuales el escritor puede realmente dialogar, pero que no es el caso de todas las fotos aparecidas en la prensa (2007:9). Y es que, como ocurre con frecuencia en la obra de Millás, la eficacia de la mirada no es un problema de naturaleza sino de espacios. 
Como en la parábola platónica, en los textos de Millás hay una concepción de la realidad basada, en principio, en la oposición entre lo real y lo ficticio. Aquello que se encuentra en el interior de esa "bóveda craneal" - es decir: dentro de esa especie de cámara oscura que es la mente humanaes una realidad modificada, recreada por la imaginación. Lo siguiente sería decir que aquello que se encuentra al exterior de esa bóveda es la realidad objetiva, y que el aprendizaje esencial del escritor sería adaptar su visión del mundo a las imágenes que la conforman. No hay que olvidar, sin embargo, que Millás concibe el cerebro humano no como la caverna que se opone al mundo idílico de las formas puras, sino como una bóveda encerrada en otra cámara oscura de dimensiones mayores.

Es en este punto donde la analogía entre el relato platónico y los artículos de Millás comienza a complicarse, pues, para él, está claro que la realidad exterior - es decir, todo lo que se encuentra fuera de la mente- está hecha de apariencias. De ahí que, si algo debe aprender quien mira, no es a distinguir lo falso de lo verdadero sino a establecer conexiones entre ambos mundos. Abrir pasillos, construir vasos comunicantes, pero sin asimilar lo falso a lo imaginario ni lo verdadero a lo supuestamente objetivo. Millás sabe que las fotografías son sombras de la realidad, pero no se engaña pensando que su trabajo como intérprete consiste en restituir para el lector aquello que "de verdad" ocurrió. Se trata, más bien, de asumir que vivimos en un mundo sin pies ni cabeza, donde lo falso parece tener más sentido que lo verdadero, y donde lo verdadero queda oculto tras la pretensión de realidad de la política, la economía y los medios informativos.

Los artículos reunidos en los libros que analizo denuncian un universo gobernado por un sofisma. La oposición maniquea entre buenos y malos impuesta por la mayor potencia del mundo y sus aliados (entre los que se contaba, no hay que olvidarlo, el gobierno de José María Aznar) tiene como sustento principal un problema que Millás expresa con claridad en una entrevista y que resuena en cada uno de sus artículos: "Nuestro modelo de democracia es Estados Unidos ¿Eso es un decorado o una democracia de verdad?" (Mauleón, en línea). Tal vez, la respuesta más firme se encuentre en el artículo "La falsa víctima propiciatoria" que acompaña la célebre foto en la que el presidente George W. Bush sostiene una charola con un falso pavo horneado.

La estrategia mediática del gobierno de Bush — exhibir un pavo de plástico ante sus tropas en Bagdad para tomarse una foto en el día de Acción de Gracias - es el punto de apoyo para una divertida reflexión sobre la ilegitimidad de la guerra contra Irak. El pavo de plástico — es decir, la "falsa víctima propiciatoria" del título - aparece, aquí, como un emblema de todas las falsedades del discurso oficial para legitimar la intervención militar. 


\section{Teresa González}

Asimilado a la piratería - "Justo en el momento de mayor sensibilización contra el pirateo de discos y zapatillas deportivas y de pantalones vaqueros, se presentó Bush en Irak con el pavo falso de la foto" (2005:49) — el gesto del presidente es la prueba de que el mundo no funciona como debería

En un mundo como Dios manda, la falsificación de la ofrenda animal en una fecha tan señalada para los norteamericanos le habría costado el puesto a Bush y a todo su equipo (¿se imaginan ustedes a Abraham ofreciendo en sacrificio a Dios un cordero de plástico?). Sin embargo, el gesto de Bush fue vendido al electorado como una travesura sin que nadie llegara a preguntarse cuál era, a partir de ahí, el límite de la mentira ¿Se puede mentir sobre la verdadera naturaleza de una víctima propiciatoria y decir la verdad sobre la naturaleza de una guerra? (2005:51)

El tour de force de Millás consiste, entonces, en buscar los rasgos de verdad que pueda haber en medio de tantas falsificaciones abriendo un canal entre la oposición entre verdad y mentira: lejos de limitarse a describir las fotos y a denunciar la falsedad que ostentan, el escritor agrega una sombra más a las sombras ya existentes. En efecto, Millás apuesta por el uso de la ficción literaria para desmitificar las imágenes periodísticas que pretenden mostrar una verdad objetiva. Así, en muchos de los artículos - especialmente los recopilados en los dos últimos volúmenes - los protagonistas de las fotos se convierten en personajes a los que Millás otorga una voz que, al final de cuentas, resulta más honesta que la que tienen en realidad.

Un ejemplo de lo anterior es el artículo "Nos preocupa la infancia", en el que aparecen varios prisioneros — entre ellos dos niños- con los ojos vendados, en cuclillas, las manos atadas por detrás de la espalda y vigilados por dos encapuchados armados. Mediante la primera persona del plural, la voz enunciadora del artículo habla desde la perspectiva de la comunidad representada por los vigilantes: la de aquellos españoles convencidos de la validez de la guerra en Medio Oriente. Con una gran dosis de ironía, esta voz desmiente las apariencias mostradas por la fotografía: aunque parezca que las víctimas son los prisioneros y los guardias, los terroristas, la voz enunciadora deja bien claro que las cosas no son como parecen

Los niños que permanecen en cuclillas, con las manos atadas a la espalda y los ojos vendados, son iraquíes malos. Los adultos de las pistolas y el rostro cubierto con pasamontañas son los buenos. Si les quitáramos el pasamontañas, veríamos las caras de Bush, o de Blair. La de Zapatero no, porque Zapatero retiró vergonzosamente nuestras tropas de Irak al día siguiente de llegar a la Moncloa. De ahí que haya 


\section{Periodismo, ficción y realidad}

sólo dos vigilantes, en lugar de tres, que sería lo suyo si comparamos el número de buenos de esta foto con el de las Azores. Una vez más, hemos perdido el tren de la historia (2006:19).

El discurso adoptado es, evidentemente, el del gobierno de José María Aznar $^{1}$, quien aparece junto George Bush y Tony Blair en la foto a la que se refiere Millás que comenta en el artículo "El trío calavera" (2006:84-87). ${ }^{2}$ En otros textos similares, la voz enunciadora asumirá postulados de un neoconservadurismo unas veces mundial, otras específicamente español, que ve con indiferencia la llegada - masiva o no- de inmigrantes del Tercer Mundo, la situación dramática de Palestina, las hambrunas en África, la pena de muerte o la segregación racial. Se trata, en suma, de situarse, siempre irónicamente, "del otro lado" —entendiendo ese "otro lado" como la postura ideológica opuesta a la del autor- para echar luz sobre sus incongruencias. ${ }^{3}$

Y es que, para Millás no hay dudas. Vivimos en un mundo marcado por las diferencias entre ricos y pobres, entre poderosos y débiles, entre los países que siguen el modelo de la falsa democracia y los que acaban siendo víctimas del orden hegemónico. España, tema al que dedica una buena parte de sus reflexiones ideológicas, no es la excepción en este mundo de oposiciones. En este sentido, el artículo "Las dos Españas" resume la postura que Millás

\footnotetext{
${ }^{1}$ Para argumentar a favor de su polémica decisión de alinearse con George W. Bush y Tony Blair en la intervención en Irak, el entonces Presidente de Gobierno José María Aznar dijo en un discurso ante una representación empresarial en La Moncloa, en abril de 2003: "España tiene hoy una consideración y respeto internacional, y puede aumentar su presencia en el mundo [...] España debe llegar al tren de la historia a tiempo" (Aizpeolea, en línea).

${ }^{2}$ Se trata de la fotografía que Sergio Pérez Sanz tomó de los tres mandatarios durante la reunión de las Azores y que obtuvo el Premio Ortega y Gasset de Fotografía. Al igual que en "La víctima propiciatoria", al que nos hemos referido en líneas anteriores, en "El trío calavera" la imagen y su contexto son la prueba, para Millás, de que el mundo está de cabeza: "Si el mundo fuera un lugar como Dios manda", escribe el autor, "esta fotografía no sólo habría obtenido el Premio Ortega y Gasset, sino que estaría colgada en las paredes de todos los aeropuertos y de todas las estaciones del mundo señalando a estos individuos como un trío peligrosísimo para la salud del universo. El mundo sería sin ellos un lugar más seguro (2005: 87).

${ }^{3}$ Llama la atención que el uso de la ironía y la recreación lúdica de discursos opuestos a su propia ideología lo lleven a hablar desde el punto de vista de un habitante del "primer mundo". En el artículo "El cóndor pasa", por ejemplo, el narrador dice que los muertos durante las manifestaciones contra la exportación de gas a Estados Unidos "son muertos digeridos y olvidados hace meses por los del lado de acá de la barricada, cuyos hábitos de consumo informativo nos obligan a una dieta constante de noticias, desgraciadas o no, que duran en la conciencia lo que un canapé de caviar en el estómago" (2005:39). Sin embargo, la posición ética del escritor parece estar precisamente del "lado bueno" de esa barricada que separa "el lado de los insurgentes del de los sumisos; el de los pobres del de los ricos; el de los indígenas del de los colonizadores, de la razón del de la locura" (2005:37-38).
} 


\section{Teresa González}

asume en textos dedicados a la política española, al poder que la Iglesia Católica - insiste - tiene tanto en la vida pública como en la privada, a la persistencia del franquismo y a las crueldades de la economía de consumo.

Se trata, como veremos, de una postura radical, deliberadamente maniquea y de izquierdas, que no oculta su simpatía por el gobierno de Rodríguez Zapatero y su aversión por el PP y sus representantes. En la siguiente cita, Millás ve en las ministras socialistas — que habían posado en ropa de diseñador en un número de la edición española de Vogue - una expresión de dos realidades tan opuestas como el día y la noche

Verdaderamente, continúa habiendo dos Españas. Una es la España satinada, sutil, sedosa, limpia y optimista de las ocho ministras que posaron de forma absolutamente discreta (no se dejen engañar: vean el reportaje) para Vogue, y otra es la España casposa, cutre, maloliente, meapilas, inculta, tétrica, antigua y funeraria que representa este individuo [Mariano Rajoy]. ¿Cuál de ellas le hiela el corazón? $(2005: 139){ }^{4}$

La cita anterior basta para afirmar que — según Millás - el mundo que se encuentra fuera de la "bóveda craneal" es un mundo absurdo, un mundo que no es "como Dios manda". Lo que parece bueno es, en realidad, malo; los políticos que se pasean por el mundo con cara de gente honesta son unos pillos [Cfr. el artículo "Condolencia Arroz", en donde la Secretaria de Estado norteamericana aparece como una "criminal agazapada tras la puerta" (2005:126)] y el modelo político y económico que rige el funcionamiento global no es otra cosa que un decorado. Ante tantas evidencias de falsedad, al intérprete no le queda más remedio sino refugiarse en esa otra caverna que es la ficción.

En estos tres volúmenes, en efecto, persiste la idea de que las pocas verdades que puede encontrar la mirada se encuentran, precisamente, en

\footnotetext{
${ }^{4}$ El uso de la disyuntiva que observamos en este fragmento es similar a la que emplea Millás en "Usted no tiene corazón", artículo compilado en Todo son preguntas. La foto comentada que, por cierto, aparece también en la portada del libro, fue tomada el 5 de marzo de 2004 durante una manifestación de los alumnos de secundaria contra la política educativa del PP y muestra a una muchacha sonriente que atraviesa un cerco policial para saludar a alguien situado fuera del marco de la imagen. La alegría y la espontaneidad de la muchacha (a quien vemos de frente) contrasta con la serie de policías uniformados que figuran de espaldas; este contraste simboliza, para Millás, dos mundos diferentes que exigen una toma de posición de parte del lector. Al principio del artículo, el autor lanza el siguiente desafío: "Si usted es aficionado a los tests y quiere averiguar en dos segundos si es idiota, pregúntese del lado de quién se pondría en esta foto. Si se queda con los cráneos de plomo frente a la sonrisa que rompe en mil pedazos la monotonía de los uniformes, usted es idiota, con perdón, y seguramente no tiene remedio. Hágase ver de todos modos”. (2005: 61)
} 
aquello que la opinión general suele considerar como falso o, sencillamente, como accesorio. Así, la responsabilidad que la sociedad pide a los políticos no se encuentra en los funcionarios de carne y hueso, como podría creerse, sino en los muñecos del célebre programa televisivo "Las noticias del guiñol", y la sensatez reinará en la vida política española cuando las elecciones las ganen los muñecos de guiñol y los políticos reales "se ganen la vida imitando a sus guiñoles en un programa de TV al que llamarán "Las noticias de carne y hueso" (2005:71). Del mismo modo que, según Millás, el "verdadero" rostro de la Princesa de Asturias aflora en una foto donde sale sacando la lengua, en un gesto divertido y despreocupado ("esta fotografía es única, pues señala ese instante en el que, al no haber dejado de ser Letizia Ortiz, tenía muchos motivos de alegría frente a la perspectiva de dejar de serlo"), la verdad está en esos gestos que el fotógrafo, y luego el escritor, consiguen arrancar al decorado en el que vivimos (2005:67).

A la falsedad del mundo exterior, varios artículos de la colección opondrán un mundo cerrado y hermético que ofrece un refugio seguro contra una realidad adversa: tal es la ficción. Vitrinas, casas de muñecas, vientres maternos. Millás aprovecha la menor oportunidad para añorar ese interior fantástico poblado por maniquíes, muñecos que parecen seres de carne y hueso; mundos ficticios como los creados por la publicidad, el cine, la literatura o la fotografía. "Cuando el realismo sucio ataca dentro y fuera", leemos a la nota, "es un respiro tropezar con la fotografía de un escaparate". (2007:79). La bondad y la despreocupación de las maniquíes de la foto llevan al autor a desear vivir entre ellas, en un mundo formado por vitrinas que se comunicaran entre sí. En otro de los artículos, el escritor imagina haberse transformado en un maniquí y afirma que el mundo de los aparadores es menos falso que el de los seres de carne y hueso. "Vivimos ahí ellas y yo, en un mundo que tiene la elegancia antigua del blanco y el negro, pero somos más reales que las dos mujeres de verdad que pasan por delante del escaparate" (2006:94).

Los espacios cerrados se convierten, así, en avatares de una caverna maternal y protectora que es, también, una metáfora de la ficción literaria. No es casualidad que en los dos artículos que comentan fotos de mujeres embarazadas (sobre la cineasta Icíar Bollaín, el primero; sobre Letizia Ortiz, el segundo) el crecimiento del feto se asimile a la creación. Para Millás, en efecto, entre la película que la cineasta acababa de terminar al ser fotografiada y su hijo Liam (que la directora esperaba mientras filmaba Te doy mis ojos) habría "un intercambio de energías impalpables", de manera que el crecimiento de uno habría influido sobre los avances de la otra y viceversa. No es un azar tampoco que, en una foto de la princesa de Asturias 


\section{Teresa González}

embarazada, Millás asocie la historia que la monarquía española empezó a construir a partir de la boda de los príncipes y la escritura de una novela

"Los procesos narrativos y los biológicos son muy semejantes. Un óvulo recién fecundado en el vientre y una idea novelesca recién aparecida en la cabeza son muy poca cosa en apariencia, pero ahí está toda la información de lo que será el relato, o la persona" (2006:107).

La caverna, las vitrinas, el útero y esa dimensión de la realidad que es la imaginación revelan buena parte de su significado cuando, en el artículo "Dentro del armario", leemos el comentario de Millás sobre un anuncio publicitario donde aparece el dibujo de una mujer desnuda, riéndose, al tiempo que - sentada en un taburete - se cubre los pechos con los brazos. Además de la mujer, en la habitación en la que se encuentra hay un armario con espejos en las puertas. Para Millás, esta imagen es, a la vez, un territorio y un mapa que no es real, pero que ordena el absurdo, lo jerarquiza y lo articula. Es, explica el autor, un microclima "no importa el tiempo que haga fuera. Dentro se está siempre a la temperatura ideal porque esta página tiene también algo de útero" (2006:73).

Los artículos recopilados en estos tres volúmenes, pues, se construyen sobre una concepción dicotómica de la realidad que encuentra su expresión simbólica en la distinción espacial dentro/fuera. La asociación entre la realidad y el espacio remite, explícitamente, a la imagen platónica de la caverna en la medida en que ésta plantea la existencia de un mundo de sombras cuyo referente se encuentra en otro plano espacial. Las nociones de interior y exterior, a su vez, sirven a Millás para situar simbólicamente la ficción, que el novelista no duda en asimilar con cavernas protectoras y maternales, y la realidad donde el autor sitúa todas las incongruencias de la política mundial. La ingenuidad deliberada y maniquea con la que la realidad es percibida, por otra parte, no hace sino reforzar el esquema bipartito que estructura la serie de artículos.

Por otra parte, entendida como un espacio, la ficción no sólo protege al escritor de la intemperie de la realidad sino que le ayuda a comprenderla e, incluso, a modificarla. La ironía y el franco humor que permean cada uno de los textos se convierten, además, en un antídoto eficaz contra los claroscuros demasiado marcados del mundo que retrata Millás, pues la advertencia de que fuera de la caverna no hay más que sombras y la sospecha de que, más allá de esas sombras, otros simulacros esperan su turno para manifestarse, permiten al lector entrar en el juego de la imaginación como contrapeso de la cotidianeidad. 
No estamos, sin embargo, ante un mero juego literario, pues dejarse interrogar por las fotografías y, en general, por todas las sombras que pueblan nuestro mundo, es para Millás una forma de intervenir en él, señalando su falsedad y proponiendo un cambio de perspectiva. Marcar los límites espaciales para, luego, trasgredirlos. Tal es, en suma, la apuesta ética de un escritor que, a fin de cuentas, encuentra en la ficción literaria una herramienta para tantear entre las sombras y vislumbrar, en medio de tanto simulacro, algunas verdades luminosas.

\author{
Universidad de Guadalajara* \\ Departamento de Estudios Literarios \\ Lerdo de Tejada 2121, Col. Americana \\ 44150 Guadalajara (México) \\ Liboria_maple@yahoo.com.mx
}

\title{
BIBLIOGRAFÍA
}

AIZPEOLEA, L. R. "El presidente justifica el apoyo de España por la necesidad de "aumentar su presencia en el mundo". El País, 8 de abril de 2003 (consultado el 18 de septiembre de 2007)

$<$ http://www.elpais.com/articuloCompleto/espana/presidente/justifica/apoyo/ Espana/necesidad/aumentar/presencia/mundo/elpepiesp/20030408elpep inac 5/Tes $>$

DE MAULEÓN, Héctor. "Entrevista con Juan José Millás". El Universal, martes 28 de noviembre de 2006 (consultado el 18 de septiembre de 2007) $<$ http://www.eluniversal.com.mx/cultura/50665.html $>$

MILLÁS, Juan José. "El síndrome de Antón”, en Trilogía de la soledad, México, Alfaguara, 1996, 9-21.

------ Todo son preguntas. Barcelona: Península, 2005.

------ El ojo de la cerradura. Barcelona: Península, 2006.

------- Sombras sobre sombras. Barcelona: Península, 2007.

SONTAG, Susan. Sobre la fotografía. México: Alfaguara, 2006. 